\title{
Mefloquine interferes with glycolysis in schistosomula of Schistosoma mansoni via inhibition of enolase
}

\author{
THERESIA MANNECK ${ }^{1,2}$, JENNIFER KEISER ${ }^{1,2} *$ and JOACHIM MÜLLER 3 \\ ${ }^{1}$ Department of Medical Parasitology and Infection Biology, Socinstrasse 57, Swiss Tropical and Public Health Institute, \\ CH-4051 Basel, Switzerland \\ ${ }^{2}$ University of Basel, Petersplatz 1, CH-4003 Basel, Switzerland \\ ${ }^{3}$ Institute of Parasitology, University of Berne, Länggass-Strasse 122, CH-3012 Berne, Switzerland
}

(Received 3 October 2011; revised 31 October 2011; accepted 1 November 2011; first published online 6 February 2012)

SUMMARY

The antimalarial drug mefloquine has promising antischistosomal properties killing haematophagous adult schistosomes as well as schistosomula. The mode of action and involved drug targets of mefloquine in Schistosoma mansoni schistosomula are unknown. In order to identify mefloquine-binding proteins and thus potential drug targets, mefloquine affinity chromatography with $S$. mansoni schistosomula crude extracts was performed. We found one specific mefloquine-binding protein that was identified by mass spectrometry as the glycolytic enzyme enolase (Q27877). Enolase activity assays were performed on schistosomula crude extracts and on the recombinant enolase Q27877 expressed in Escherichia coli. In schistosomula crude extracts enolase activity was inhibited by mefloquine and by the enolase inhibitor sodium fluoride, while activity of the recombinant enolase was not affected. In contrast to enolase from crude extracts, recombinant Q27877 did not bind to mefloquine-agarose. Using isothermal microcalorimetry, we next investigated the metabolic inhibition of mefloquine and 3 known glycolytic inhibitors in Schistosoma spp., namely sodium fluoride, 3-bromopyruvate and menadione on schistosomula in the presence or absence of glucose. We found that in the presence of glucose, schistosomula were less affected by mefloquine, sodium fluoride and 3-bromopyruvate, whereas glucose had no protective effect when schistosomula had been exposed to menadione. These results suggest a potential role of mefloquine as an inhibitor of glycolysis, at least in stages where other targets like haem degradation are not relevant.

Key words: Schistosoma mansoni, affinity chromatography, mefloquine, drug target, enolase, metabolic inhibition, isothermal microcalorimetry, glycolysis.

\section{INTRODUCTION}

Antischistosomal chemotherapy is still restricted to the use of praziquantel. The antimalarial drug mefloquine, a synthetic analogue of quinine has promising antischistosomal activity in vitro and in vivo (Keiser et al. 2009, 2010; Xiao et al. 2011). The mode of action and the target of mefloquine in Schistosoma spp. are, however, not known. Knowledge of the drug target might, however, aid in the design and discovery of novel antischistosomal drugs (Renslo and McKerrow, 2006; Sleno and Emili, 2008).

There is good evidence that in Plasmodium spp. mefloquine interferes with haemoglobin degradation. Toxic haem is released when the parasite feeds on haemoglobin. The haem is rapidly oxidized to haemin and subsequently converted to haemozoin. In the presence of mefloquine the conversion of free haem to haemozoin is inhibited. As a consequence, toxic haem and haemin complexes accumulate and

* Corresponding author: Department of Medical Parasitology and Infection Biology, Socinstrasse 57, Swiss Tropical and Public Health Institute, CH-4051 Basel, Switzerland. Tel: +4161284 8218. Fax: +41612848105. E-mail: jennifer.keiser@unibas.ch kill the parasite (Dorn et al. 1998; Zhang et al. 1999; Pasternack et al. 2010).

Schistosomes feed on blood and haem is detoxified into large insoluble crystals identical to Plasmodium haemozoin (Oliveira et al. 2000). Therefore, a similar mode of action of mefloquine in both parasites is probable. A recently conducted in vitro study suggests that mefloquine interferes with the haem detoxification pathway in Schistosoma mansoni, since a more pronounced activity of the drug was observed against $S$. mansoni in the presence of haemin (Manneck et al. 2011a). However, mefloquine also shows high in vitro activities on 1 -day-old $S$. mansoni schistosomula and on adult schistosomes without addition of haemin or red blood cells. In fact, RNAi studies have shown that schistosomula show an extensive uptake of exogenous material into the gut immediately after transformation of cercariae into schistosomula. Haemoglobin-derived pigment is present in the gut of 2-day-old schistosomula, but there is no evidence for blood uptake at earlier timepoints (Stefanic et al. 2010). This suggests that the drug may have targets independent of haemoglobin digestion.

The purpose of the present work was to identify targets for mefloquine in 1-day-old, most likely 
non-haem feeding S. mansoni schistosomula. Schistosomula can easily be produced by mechanical transformation of cercariae obtained from infected Biomphalaria glabrata snails (Keiser, 2010).

Here, we present a mefloquine affinity chromatography study (Müller et al. 2008) in order to identify mefloquine-binding proteins in schistosomula and report on the identification of $S$. mansoni enolase (EC 4.2.1.11; Q27877) as a major mefloquinebinding protein. Enolase is the enzyme catalysing the conversion of phosphoglycerate to phosphoenolpyruvate in the Embden-Meyerhoff-Parnas pathway of glycolysis. These investigations were complemented by functional enolase assays and by isothermal microcalorimetry studies (Manneck et al. 2011b).

\section{MATERIALS AND METHODS}

\section{Parasite}

The $S$. mansoni life cycle is maintained at the Swiss Tropical and Public Health Institute in Basel, Switzerland. The intermediate host snails (Biomphalaria glabrata) were exposed to light for approximately $3 \mathrm{~h}$ around noon and subsequently cercariae of $S$. mansoni were harvested.

\section{Chemicals and drugs}

Mefloquine hydrochloride $(414 \cdot 81 \mathrm{~g} / \mathrm{mol})$ was kindly provided by Mepha Pharma AG (Aesch, Switzerland). Penicillin/streptomycin solution and M199 culture medium are products from Gibco/ Invitrogen (Carlsbad, USA) obtained by Lubio Science $\mathrm{GmbH}$ (Lucerne, Switzerland). If not otherwise stated, all chemical reagents were from Sigma-Aldrich Chemie GmbH (Buchs, Switzerland). Drug stock solutions were prepared in DMSO or water and stored at $-20^{\circ} \mathrm{C}$.

\section{Preparation of S. mansoni schistosomula}

Cercariae of $S$. mansoni were mechanically transformed into schistosomula by repeat vortexing as described previously (Keiser, 2010; Manneck et al. 2010). The schistosomula were then kept in M199 culture medium supplemented with $5 \%$ heatinactivated foetal calf serum and $100 \mathrm{U} / \mathrm{ml}$ penicillin and $100 \mu \mathrm{g} / \mathrm{ml}$ streptomycin at $37^{\circ} \mathrm{C}$ in an atmosphere of $5 \% \mathrm{CO}_{2}$ for a minimum of $3-12 \mathrm{~h}$, to assure that transformation into the schistosomular stage was completed. Afterwards the parasite suspension was centrifuged $(8000 \boldsymbol{g}, 5 \mathrm{~min}$, room temperature), washed twice with phosphate-buffered saline (PBS), and followed by another centrifugation step. The pellet was stored at $-20^{\circ} \mathrm{C}$.

\section{Isothermal microcalorimetry}

A 48-channel isothermal microcalorimeter (Model TAM 48, TA Instruments, New Castle, Delaware,
USA) was used to measure the production of heat by $S$. mansoni schistosomula incubated with 1 of 3 different glycolytic inhibitors, namely fluoride (1 and $20 \mathrm{mM})$, menadione $(50 \mu \mathrm{M})$ and 3-bromopyruvate $(0.5 \mathrm{mM})$ or mefloquine $(24$ and $48 \mu \mathrm{M} ; 10$ and $20 \mathrm{mg} / \mathrm{l})$. Untreated schistosomula and dead parasites served as controls. Parasites were killed with ethanol and death was confirmed by microscopical evaluation as described previously (Manneck et al. 2011a). Pure medium represented the background control. The calorimeter and the injection system were described in detail in a previous publication (Manneck et al. 2011b). Briefly, glass ampoules were filled with $1800 \mu \mathrm{l}$ of culture medium M199 with or without glucose supplementation $(20 \mathrm{mM})$. Then $100 \mu \mathrm{l}$ of schistosomula suspension containing approximately 600 schistosomula were added. Ampoules were placed into the measuring channels and when a stable signal was obtained (approximately after $12 \mathrm{~h}$ ), $100 \mu \mathrm{l}$ of medium containing different volumes of drug stock solution or of DMSO (as a solvent control) were injected into the ampoules. Heat-flows with 1 data point per $10 \mathrm{~min}$ were recorded for $96 \mathrm{~h}$ at maximum. Heat-flow curves of treated and untreated parasites were examined before and after addition of drug. Heat-production of schistosomula treated with the compound alone or in the presence of glucose were compared $24 \mathrm{~h}$ after drug addition. All samples were analysed in triplicate.

\section{Preparation of schistosomula crude extracts}

For protein extraction, frozen schistosomula pellets were re-suspended in ice-cold extraction buffer consisting of PBS, $1 \%$ Triton-X-100, and a protease inhibitor cocktail (Halt, Thermo Scientific, Rockland, IL, USA). Suspensions were vortexed thoroughly following repeated freezing on dry iceisopropanol and thawing. After 3 cycles of freezing and thawing, the suspension was centrifuged $\left(15200 \mathrm{~g}, 10 \mathrm{~min}, 4^{\circ} \mathrm{C}\right)$. Supernatants were collected, and extraction of pellets was repeated twice. The supernatants were combined and subjected to enolase assays or to mefloquine-agarose affinity chromatography. For affinity chromatography, approximately $8 \cdot 5 \times 10^{5}$ parasites (10 transformation procedures with 70-90 intermediate host snails each) were extracted in $3 \times 1 \mathrm{ml}$ of extraction buffer. For enolase assays less parasites (about $4 \times 10^{5}$ schistosomula) and accordingly modified extraction volumes were used.

\section{Affinity chromatography with $\mathrm{S}$. mansoni schistosomula crude extracts on mefloquine-epoxy agarose}

In order to produce mefloquine-agarose, $0 \cdot 3 \mathrm{~g}$ lyophilized epoxy-agarose with a C-12-spacer was suspended in $15 \mathrm{ml}$ of $\mathrm{H}_{2} \mathrm{O}$ and centrifuged at $300 \boldsymbol{g}$ for $5 \mathrm{~min}$. Washes in water were repeated twice, and 
the suspension was washed once in coupling buffer $\left(\mathrm{NaHCO}_{3} 0 \cdot 1 \mathrm{M}, \mathrm{pH} 9 \cdot 5\right)$. After the last wash, epoxyagarose was suspended in $2 \mathrm{ml}$ of coupling buffer. Twenty $\mathrm{mg}$ mefloquine were dissolved in $2 \mathrm{ml}$ of dimethyl-formamide and added to the agarose. The mixture was incubated for 3 days at $37^{\circ} \mathrm{C}$ under slow but continuous shaking in order to allow coupling of the epoxy group to mefloquine via the $\mathrm{OH}$ - group of the piperidine-2-yl-methanol part of the molecule. For the negative control a mock column was prepared by blocking a column with ethanol-amine only (Müller et al. 2008). Prior to the runs, both columns (bed volumes ca. $1 \mathrm{ml}$ each) were combined in a tandem (mock column first, then mefloquine column) and washed with $50 \mathrm{ml}$ of PBS equilibrated at $20^{\circ} \mathrm{C}$. Then $3 \mathrm{ml}$ of schistosomula crude extract was loaded onto the column tandem at a flow rate of $0.25 \mathrm{ml} / \mathrm{min}$. The columns were washed with PBS until a flat baseline was detected (more than 10 column volumes). The columns were separated, and proteins binding to the columns were eluted with $1 \mathrm{mM}$ mefloquine in PBS followed by elution with a $\mathrm{pH}$ shift (glycine $\mathrm{Cl}^{-} 100 \mathrm{mM}, \mathrm{pH} 2.9$ ) in order to remove non-specifically bound proteins. Moreover, fractions were taken before elution with mefloquine (pre-mefloquine) and following a $\mathrm{pH}$ shift (pre-pH shift). Sizes of these fractions ranged between 3 and $5 \mathrm{ml}$. Aliquots from each fraction $(200 \mu \mathrm{l})$ and from the crude extract $(50 \mu \mathrm{l})$ were taken and analysed by SDS-PAGE. SDS-PAGE and silver staining were performed as summarized in a recent publication (Müller et al. 2008).

The protein identified in the mefloquine eluate only was then further analysed by mass spectrometry. For protein sequencing by mass spectrometry, protein was prepared (Müller et al. 2008) and sequenced by the Proteomics Core Facility, Faculty of Medicine, University of Geneva, Switzerland.

\section{Cloning and heterologous expression of recombinant}

\section{S. mansoni enolase}

Cloning, heterologous expression and His-tag purification of recombinant enolase were carried out as described (Müller et al. 2008). Briefly, in order to clone enolase into the His-tag-expression vector pET151 directional TOPO (Invitrogen, Carlsbad, CA), the primers pENOfor (CACCATGTCCATTTTAACGATCCAC) and pENOrev (TTATACTTTGGGATGGCGGAAG) were created for the amplification of a 1260 base pair product encoding the enolase (Q27877) polypeptide with 4 additional bases at the 5 'end allowing directional cloning (MWG Biotech, Ebersberg, Germany). cDNA was created from adult $S$. mansoni following a protocol by Lochmatter et al. (2009) and PCR was performed using Phusion Polymerase and the appropriate protocol (Phusion TM DNA Polymerase,
High Fidelity PCR KIT, Finnzymes). The resulting product was cloned into pET151 TOPO vector and transformed into $E$. coli TOP 10 cells (Invitrogen). Heterologous expression of enolase in positive transformants of Escherichia coli (BL21 Star) and subsequent his-tag purification of recombinant enolase was performed as previously described (Müller et al. 2008). Purified protein was stored in $50 \%$ glycerol at $-20^{\circ} \mathrm{C}$.

\section{Enolase assay}

Enolase activity was determined using an enzymatic assay coupled to pyruvate kinase and L-lactate dehydrogenase by measuring the conversion of $\mathrm{NADH}$ to NAD by the latter enzyme according to a protocol of Sigma-Aldrich. The assay was performed in a 96-well-plate containing a total volume of $250 \mu \mathrm{l}$ in each well and $80 \mathrm{mM}$ triethanolamine buffer (pH 7.4), 0.12 mM B-NADH, $25 \mathrm{mM}$ magnesium sulfate, $100 \mathrm{mM}$ potassium chloride solution, $1.3 \mathrm{mM}$ ADP, $7 \mathrm{U} / \mathrm{ml}$ pyruvate kinase, $10 \mathrm{U} / \mathrm{ml}$ of lactate dehydrogenase and enolase (crude extracts or recombinant, $2-5 \mu \mathrm{l})$. The reaction was initiated by adding the enolase substrate 2-phosphoglycerate $(0-1.8 \mathrm{mM})$. Blanks without enolase and blanks without substrate served as controls.

For inhibition studies, mefloquine and sodium fluoride were added as indicated in Fig. 3 of the results section $(24-240 \mu \mathrm{M})$. All samples were assessed in triplicate. The decrease of absorbance of NADH was recorded for $20 \mathrm{~min}$ at $340 \mathrm{~nm}$ by continuous photometric rate determination (VersaMax $^{\mathrm{TM}}$ Absorbance Microplate Reader, Molecular Devices, Sunnyvale, California, USA). Effects of mefloquine on pyruvate kinase and lactate dehydrogenase were monitored by adding phosphoenolpyruvate (final concentration of $1.8 \mathrm{mM}$ ) instead of enolase and 2-phosphoglycerate to the reaction mix.

\section{Statistics}

Pairwise $t$-tests were performed using the StatsDirect statistical software package (version 2.7.2., StatsDirect Ltd; Cheshire, UK). $\mathrm{K}_{\mathrm{m}}$ and $\mathrm{V}_{\text {max }}$ values were determined after regression analysis by the corresponding software tool contained in the Excel software package (Microsoft, Seattle, Washington, USA).

\section{RESULTS}

\section{Enolase is a major mefloquine-binding protein in} S. mansoni schistosomula

Since mefloquine was found to affect the nonhaematophagous schistosomula (Manneck et al. 2010) we aimed to identify the cellular target of this 


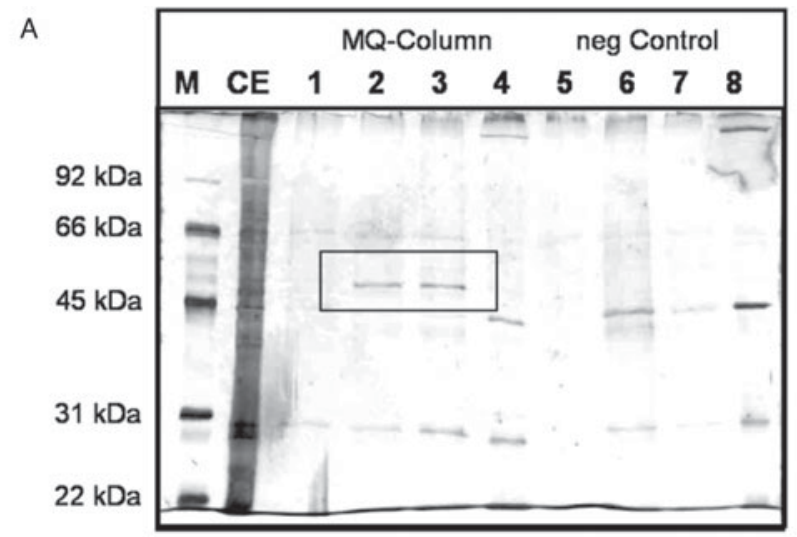

B

SCHMA MSILTIHARQIFDSRGNPTVEVDLKTSKGLFRAAVPSGASTGVHEALELRDTNSKAYMKKGVLTAVSNVNKIIAPALINKNIPVTWQAAIDKYMIDLDGTENKEKLGANA 110 SCHJA MAIIAIHARQIFDSRGNP TVEVDLKTAKGLFRAAVPSGASTGVHEALELRDTNSKAYMCKGVLTAVSNVNNIIAPALLKKQIPV TNQSEVDQFMIELDGKENKGNL GANA 110 FASHE MAIKAIHARQIFDSRGNPTVEVDVTTAKGLFRAAVPSGASTGVHEALELRDG-PPGYMGKGVLKAVANVNSQIAPNLIKSGINVTDQAAVDKFMLDLDGTPNKEKLGANA 110 HUMAN MSILKIHAREIFDSRGNPTVEVDLFTSKGLFRAAVPSGASTGIYEALELRDNDKTRYMGKGVSKAVEHINKTIAPALVSKKLNVTEQEKIDKLMI EMDGTENKSKFGANA 110

SCHMA ILGVSLAVCKAGAAEAGLPLYRY IARLAGHEDVIMPVPAFNVINGGSHAGNKLAMQEFMILPTGASSFTEAMQI GTEVYHNLKAVIKREYGLDACNVGDEGGFAPN IQDN 220 SCHJA ILGVSLAVCKAGAAELNLPLYRY IAKLAGHKDVIMPVPAFNVINGGSHAGNKLAMQEFMILPTGASSFTEAMQMGSEVYHNLKAVI KREFGLDACNVGDEGGFAPNIQDN 220 FASHE ILGVSLAXCKAGAAEKGLPLYKY IATLAGNKEVIMPVPSFNVINGGSHAGNKLAMQEFMIMPTGASSFTEAMKI GSEVYHNLRAVIKSKYGLDACNVGDEGGFAPSIQDN 220 HUMAN ILGVSLAVCKAGAVEKGVPLYRH IADLAGNSEVI LPVPAFNVINGGSHAGNKLAMOEFMIL PVGAANFREAMRI GAEVYHNLKNVIKEKYGKDAT NVGDEGGEAPNILEN 220

SCHMA MKGLQLLEEAIKIAGYTGKVEI GMDCAASEFHKNGKYDLDFKNPHSAESTWLSPDAMANMYKQMISKFPIVSIEDPFDQDDWETWPKLTSSTNIQIVGDDLTVTNPKRIK 330 SCHJA MKGLQLLEEAIKIAGYTGKVEI GMDCAASEYYKKGKYDLDFKNPQSAESHWLSPDEMANVYKEMIQKYPIVSIEDPFDQDDWDAWPKLTASTNIQIVGDDLTVTNPKRIE 33C FASHE LEGLELLRTAIDKAGYTGKVXIAMDCAASEFYKEGKYDLDFKNPKSQASSWITSDAMADVYKKMMSTYPIVSIEDPFDQDDWPAWTKLTGECKIQIVGDDLTVTNPLRVQ 330 HUMAN KEGLELLKTAIGKAGYTDKVVIGMDVAASEFFRSGKYDLDFKSP-DDPSRYISPDQLADLYKSFIKDYPVVSIEDPFDQDDWGAWQKFTASAGIQVVGDDLTVTNPKRIA 33O

SCHMA QAIASKACNCLLLKVNOIGSLTESIEACKLAQDSGWGVMVSHRSGETEDTFIADLVVGLCTGQIKTGAPCRSDRLAKYNOLLRIEEELGTAAKYAGKNFRHPKV- 434 SCHJA KAIKVKACNCLLLKVWQI GSITESIEACKMAQKAGWGVMVSHRSGETEDNFIADLVVGLCTGQIKTGAPCRSERLAKY NQLLRIEEELGSTAKYAGKHFRHPQI- 434 FASHE KAIDQKACNCLLLKVNQIGSVSESIKACKMAQEAGWGVMVSHRSGETEDNFIADLVVGLRTGQIKTGAPCRSERLAKYNQLLRIEEDLGGAAKYAGENFRRP---- 431 FASHE KAIDQKACNCLLLKVNQIGSVSESIKACKMAQEAGWGVMVSHRSGETEDNFIADLVVGLRTGQIKTGAPCRSERLAKY QLLRI EEDLGGAAKYAGENFRRP----
HUMAN KAVNEKSCNCLLLKVNQIGSVTESLQACKLAQANGWGVMVSHRSGETEDTFIADLVVGLCTGQIKTGAPCRSERLAKY QLLRIEEELGSKAKFAGRNFRNPLAK

Fig. 1. (A) SDS-PAGE of affinity chromatography eluates of Schistosoma mansoni schistosomula extracts. Eluates were obtained by mefloquine-agarose affinity chromatography (MQ-column; lanes 1-4) and by an ethanolamine coupled mock column (negative control; lanes 5-8). Marker (M), crude extract (CE), Wash plus pre-mefloquine (1 and 5), eluates with $1 \mathrm{mM}$ mefloquine (2 and 6 and 3 and 7), pH-shift with $0.1 \mathrm{M}$ glycine at $\mathrm{pH} 2.9$ (4 and 8). Bands were visualized by silver staining. (B) Protein sequence of $S$. mansoni enolase Q27877 (SCHMA) and alignment with other enolases, namely P33676 from S. japonicum (SCHJA), Q27655 from Fasciola hepatica (FASHE) and P06733 from human (HUMAN). Peptides identified by mass spectrometry are highlighted in grey.

drug in schistosomula. Mefloquine was coupled to epoxy-agarose, a mock-column was prepared, and affinity chromatography was performed with schistosomula crude extracts on both columns mounted in tandem. Both columns were washed and separately eluted with mefloquine or a low-pH buffer. The elution with low $\mathrm{pH}$ of both columns yielded bands of ca. 40 and $30 \mathrm{kDa}$. These bands were also present to various extents in mefloquine elutions. In addition, only elution with mefloquine of the mefloquine-column yielded a band of ca. $50 \mathrm{kDa}$ (Fig. 1A, rectangle). This band was subjected to mass spectrometry analysis. Eight peptides aligned with $100 \%$ protein probability to $S$. mansoni enolase Q27877 (identical to AAC46884, AAC46886, CBN61518.1) and to S. mansoni enolase C4Q3S7 (identical to XP_002573848.1, CAZ30081.1) with $23 \%$ coverage of the sequence (Fig. 1B). C4Q3S7 differed in 2 amino acids only from Q27877, namely an isoleucine instead of a threonine in position 52 and a phenylalanine instead of a tyrosine in position 93 . Q27877 was identified through an analysis of transspliced mRNAs (Davis et al. 1995), C4Q3S7 via the genomic sequencing effort (Berriman et al. 2009).
Analysis by BLAST (Altschul et al. 1997) revealed that the coding sequences for both proteins were identical (data not shown). One peptide aligned also to enolases from $S$. japonicum (P33676) and F. hepatica (Q27655), 3 aligned with the $S$.japonicum enolase only, 4 were unique to $S$. mansoni. The protein with the highest similarity in humans is alpha-enolase (P06733; Fig. 1B).

\section{Enolase activity from schistosomula crude extract is inhibited by mefloquine}

Enolase activity in parasite crude extracts was inhibited by mefloquine in a concentrationdependent manner at $24 \mu \mathrm{M}$ and above. At $240 \mu \mathrm{M}$, both mefloquine and sodium fluoride, a well-known enolase inhibitor (Warburg and Christian, 1941), nearly completely inhibited enolase activity in crude extracts (Fig. 2). The inhibition by mefloquine was not due to inhibition effects on the coupled reactions catalysed by pyruvate kinase and lactate dehydrogenase. This was shown by control assays where the product of the reaction catalysed by enolase, namely 


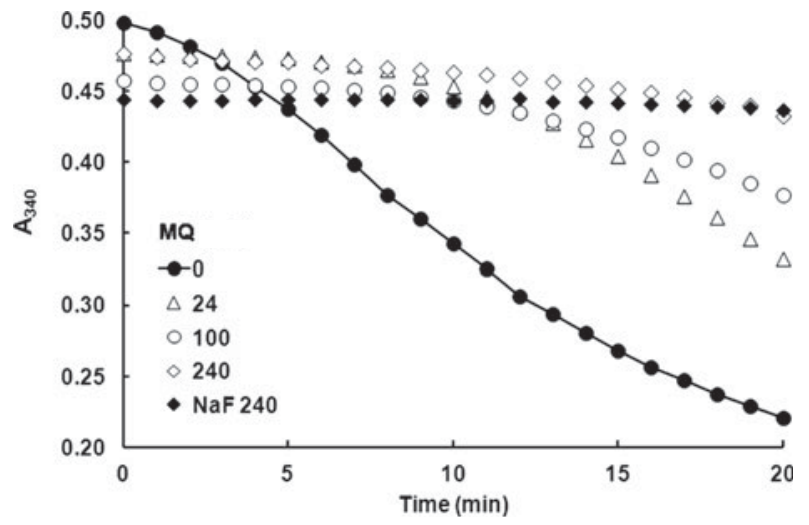

Fig. 2. Mefloquine inhibits enolase activity in Schistosoma mansoni crude extracts. Enolase assays were performed with $S$. mansoni schistosomula crude extracts in the presence of different concentrations of mefloquine (MQ $0-240 \mu \mathrm{M}$ ) or sodium fluoride as a positive control for inhibition ( $\mathrm{NaF} 240 \mu \mathrm{M})$. Data are expressed as the decrease of absorption at $340 \mathrm{~nm}$ over time.

phosphoenol-pyruvate, was added to the reaction mix instead of enolase and the substrate 2-phosphoglycerate. Activities of the coupled reactions performed without mefloquine (Control, 60.6 $\Delta \mathrm{mA}_{340} / \mathrm{min}$ $\pm 3 \cdot 5)$ or with $240 \mu \mathrm{M}$ mefloquine $\left(59 \cdot 3 \Delta \mathrm{mA}_{340} / \mathrm{min}\right.$ $\pm 4 \cdot 6)$ were identical.

Subsequently, Q27877 was over-expressed as a His-Tag protein in E. coli and affinity purified under non-denaturing conditions (Fig. 3A). The recombinant protein had enolase activity, but was not inhibited, either by fluoride or by mefloquine at $240 \mu \mathrm{M}$ (Fig. 3B). In order to see whether the recombinant enzyme had the same catalytic properties as the enolase activity in crude extracts, we performed enolase assays with both enzymes at various substrate concentrations and determined $\mathrm{K}_{\mathrm{m}}$ and $\mathrm{V}_{\max }$ values according to LineweaverBurke. Enolase from crude extracts had nearly 1 magnitude higher $\mathrm{K}_{\mathrm{m}}$ and about 5 times lower $\mathrm{V}_{\text {max }}$ values than the recombinant enzyme (Table 1). Moreover, we performed a pull-down assay on mefloquine agarose with the recombinant enolase. The protein was detected quantitatively in the flowthrough, hence the recombinant protein did not bind to the column (Fig. 3C).

\section{Glucose interferes with the antischistosomal activity of mefloquine}

Based on previously published results on metabolic inhibition of schistosomula by mefloquine, we compared the effect of mefloquine to compounds well known for interfering with glycolysis, namely sodium fluoride (Warburg and Christian, 1941) and 3-bromopyruvate (Pelicano et al. 2006). We hypothesized that a supplementation of the medium with glucose may counteract inhibition by these compounds. Additional glucose would offer more substrate for each reaction during glycolysis, increase the rate of glycolysis and might decrease the inhibitory effect of the tested glycolytic inhibitors and of mefloquine. As a control, we included menadione (Bueding, 1950) interfering with glycolysis via induction of oxidative stress (Verrax et al. 2006).

Figure 4 illustrates the relative heat production (metabolic activity of untreated control worms in the absence of glucose was set to $100 \%$ ) of schistosomula incubated with the 4 tested compounds in the presence or absence of glucose $(0$ and $20 \mathrm{mM}) 24 \mathrm{~h}$ post-incubation. The addition of glucose caused no significant increase as compared to the control group. After incubation with $24 \mu \mathrm{M}$ mefloquine in glucosefree medium, metabolic activity of schistosomula dropped to nearly one fifth of the control values. Schistosomula incubated with $20 \mathrm{mM}$ glucose showed a significantly higher metabolic activity after exposure to mefloquine as compared to schistosomula incubated in plain medium. The same effect was seen for schistosomula incubated with $48 \mu \mathrm{M}$ mefloquine. By $24 \mathrm{~h}$ post-incubation, metabolic activity of parasites incubated in glucose-free medium had decreased to less than $20 \%$ compared to control values, whereas worms exposed to mefloquine incubated in medium containing glucose had a significantly higher activity. When schistosomula were incubated with a lower concentration of $10 \mathrm{mM}$ glucose (data not shown) again a significantly higher heat-flow after exposure to mefloquine was seen, when compared to schistosomula incubated in medium without glucose. The effects of higher mefloquine concentrations could not be evaluated since these doses resulted in a rapid decrease of metabolic activity of schistosomula, which was too fast to be recordable by our system (Manneck et al. $2011 b$ ).

The addition of sodium fluoride caused a concentration-dependent decrease of the heat-flow. Incubation with $20 \mathrm{mM}$ sodium fluoride resulted in death of all schistosomula. In the presence of $20 \mathrm{mM}$ sodium fluoride plus glucose metabolic activity was still detectable. Both parasites incubated with and without additional glucose had similar metabolic activities $24 \mathrm{~h}$ after incubation with $50 \mu \mathrm{M} \quad 3$ bromopyruvate (data not shown). In the presence of $0.5 \mathrm{mM} \mathrm{3-bromopyruvate} \mathrm{metabolic} \mathrm{activity} \mathrm{was}$ nearly at background levels. In the presence of glucose and $0.5 \mathrm{mM} 3$-bromopyruvate metabolic activity was detectable at nearly $10 \%$ of the control levels. Finally, menadione $(50 \mu \mathrm{M})$ killed schistosomula $24 \mathrm{~h}$ post-incubation regardless of glucose supplementation.

\section{DISCUSSION}

Isothermal microcalorimetry, which measures the heat produced by microorganisms has proven to be a 

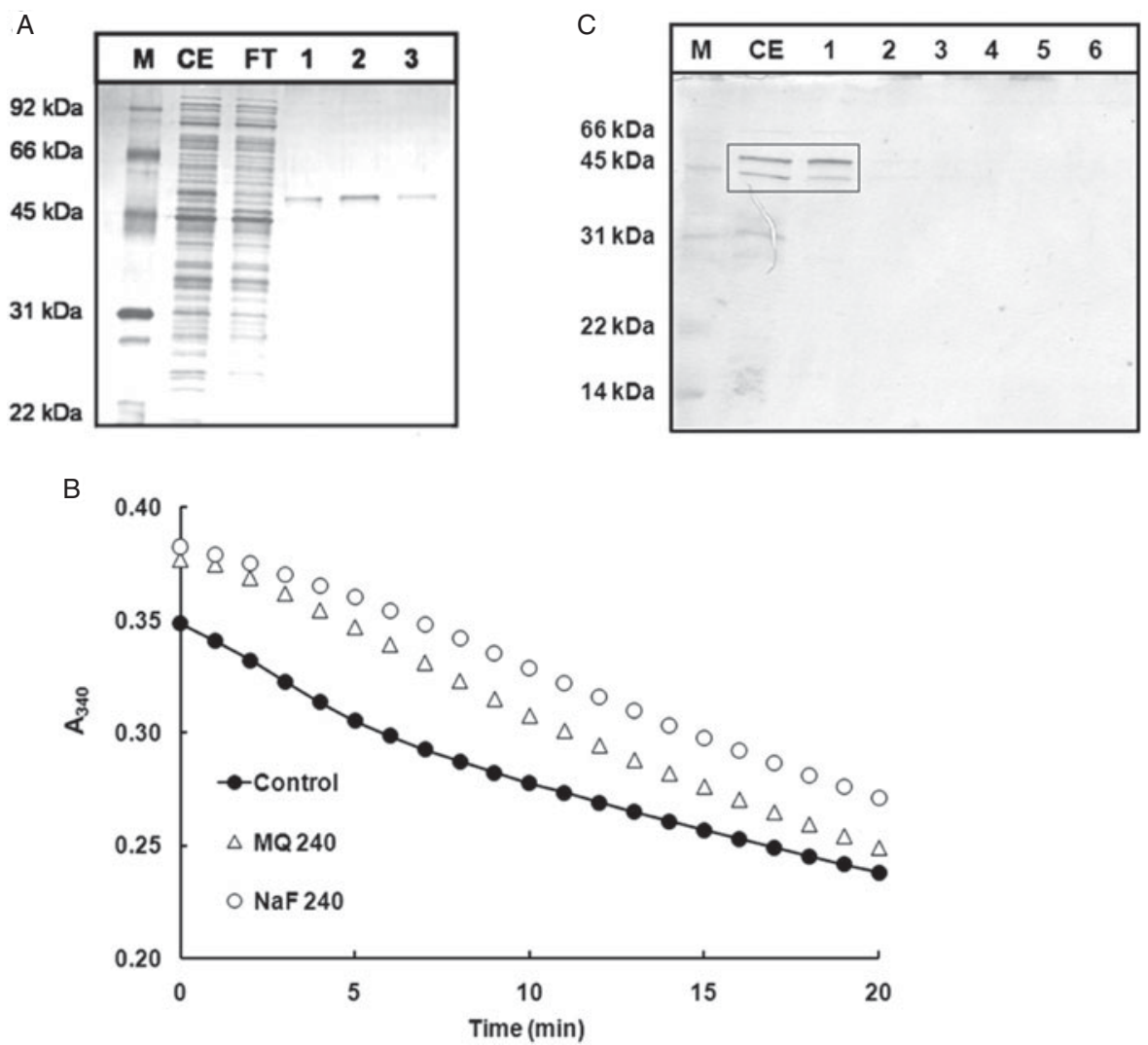

Fig. 3. Recombinant enolase Q27877 is not inhibited either by fluoride or by mefloquine. (A) SDS-PAGE of his-tag purified recombinant enolase. Marker (M), crude extract (CE), flow through (FT), eluates (1-3). (B) Enolase activity of recombinant Q27877 in the presence of $240 \mu \mathrm{M}$ mefloquine (MQ 240) or $240 \mu \mathrm{M}$ sodium fluoride (NaF 240).

(C) SDS-PAGE of mefloquine agarose affinity chromatography of recombinant enolase Q27877. Crude extract (CE), flow-through (1), wash (2), pre-mefloquine (3), mefloquine (4), mefloquine pre $\mathrm{pH}$-shift (5), $\mathrm{pH}$-shift (0.1 M glycine, pH 2.9) (6). Bands were visualized by silver staining.

Table 1. Kinetic parameters of enolase activity from Schistosoma mansoni schistosomula crude extracts and of recombinant enolase Q27877

(To determine $\mathrm{K}_{\mathrm{m}}$ and $\mathrm{V}_{\max }$ values, enolase reactions were performed with substrate concentrations ranging from $0 \cdot 1$ to $1.8 \mathrm{mM}$. The reciprocals of the resulting reaction rate $\left(\mathrm{v}_{\mathrm{i}}\right)$ values and the substrate concentrations were plotted and $\mathrm{K}_{\mathrm{m}}$ and $\mathrm{V}_{\max }$ values and the corresponding errors were calculated by regression analysis.)

\begin{tabular}{llr}
\hline \hline Parameter & Crude extract & Recombinant \\
\hline $\mathrm{K}_{\mathrm{m}}(\mathrm{mM})$ & $3 \cdot 22 \pm 0 \cdot 21$ & $0 \cdot 21 \pm 0 \cdot 05$ \\
$\mathrm{~V}_{\max }(\mathrm{mkat} / \mathrm{mg}$ prot $)$ & $95 \cdot 2 \pm 26 \cdot 2$ & $485 \cdot 2 \pm 81 \cdot 5$ \\
\hline \hline
\end{tabular}

suitable method to evaluate the activity of antischistosomal compounds (Manneck et al. 2011b). Energy acquisition in schistosomes is provided mainly via glycolysis (Bueding, 1950; Van den Bossche, 1985; Yang et al. 2010). Compounds interfering with glycolysis thus rapidly block muscular contraction and heat development. We have investigated a series of compounds directly interfering with glycolysis, namely sodium fluoride, 3-bromopyruvate, and

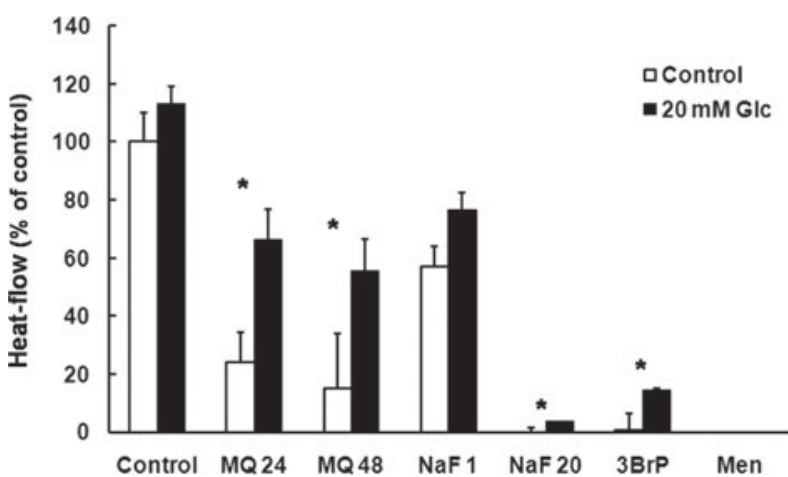

Fig. 4. Heat-flow of Schistosoma mansoni schistosomula $24 \mathrm{~h}$ post-incubation with $24 \mu \mathrm{M}$ (MQ 24) and $48 \mu \mathrm{M}$ mefloquine (MQ 48), $1 \mathrm{mM}$ or $20 \mathrm{mM}$ sodium fluoride ( NaF 1, NaF 20), 0.5 mM 3-bromopyruvate (3-BP), or with $50 \mu \mathrm{M}$ menadione (Men) in the absence of glucose (Control) or with glucose (20 mM Glc). Mean values \pm s.E. are indicated for 4 replicates. Values with significant differences $(t$-tests; $P<0 \cdot 05)$ between samples with and without additional glucose are labelled with asterisks.

menadione on schistosomula using microcalorimetry. Sodium fluoride is a well-characterized inhibitor of enolase, the enzyme catalysing the 


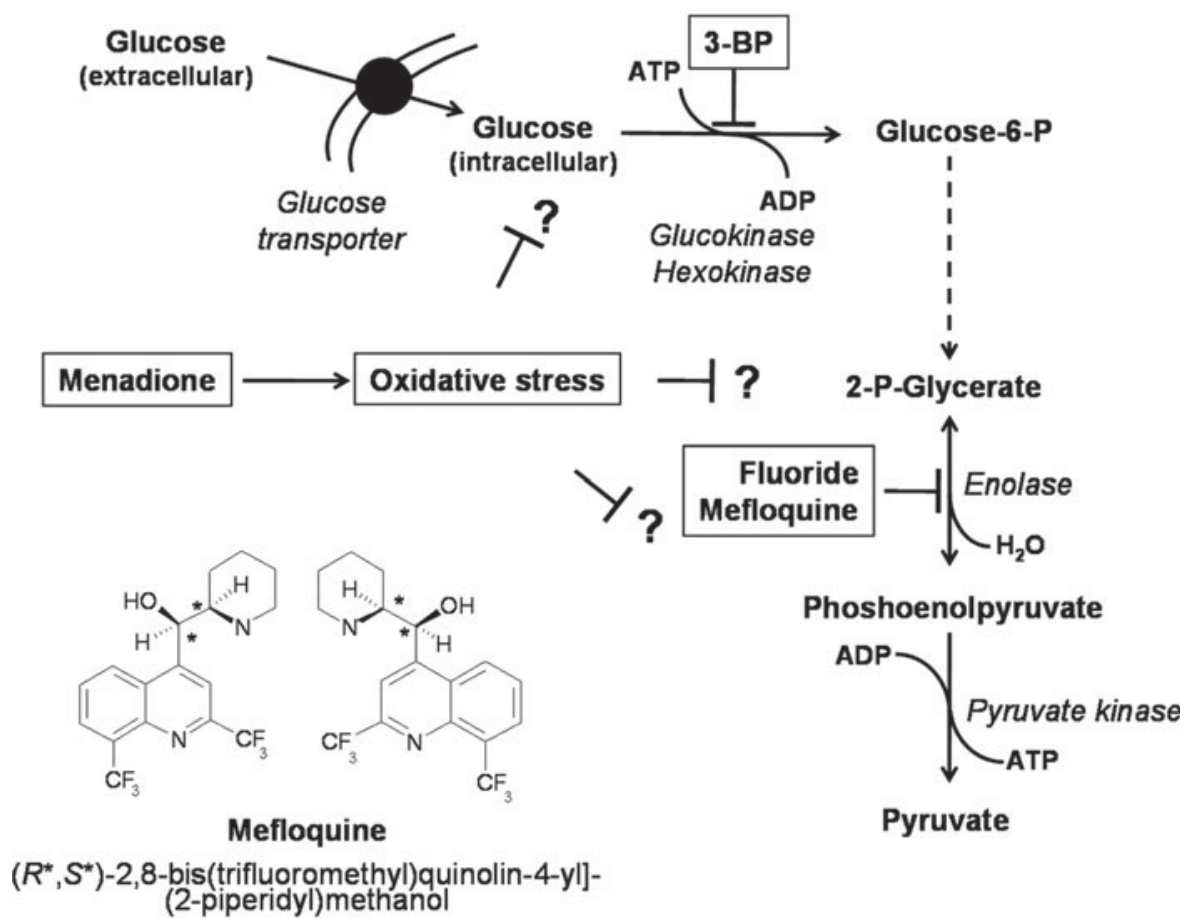

Fig. 5. Scheme summarizing glycolysis in Schistosoma and targets for inhibitors (in rectangles) as used in the present study. A structural formula of mefloquine is shown.

conversion of phosphoglycerate to phosphopyruvate (Warburg and Christian, 1941). However, sodium fluoride is not selective to enolase and inhibits a variety of other enzymes such as phosphatases or ATPases. Therefore, the reduction of glucose consumption in schistosomula may also be due to effects of sodium fluoride on other metabolic pathways. In adult schistosomes, sodium fluoride reduces the consumption of glucose and the production of lactate (Bueding, 1950). Menadione is a naphthoquinone with structural similarities to mefloquine. Similar to sodium fluoride, it reduces glucose consumption and lactate production in adult schistosomes (Bueding, 1950), but most likely not by an inhibition of glycolysis but instead by an induction of oxidative stress (Verrax et al. 2006). 3-bromopyruvate inhibits hexokinase in the glycolytic pathway and decreases the ATP content in cells by inhibition of ATP production and depletion of cellular ATP. Due to its cytotoxic activity against cancer cells, pre-clinical trials have been launched to confirm its activity for anticancer treatment (Pelicano et al. 2006). To our knowledge, the antischistosomal activity of 3-bromopyruvate has not been described so far. Our microcalorimetric studies reveal that simultaneous addition of glucose attenuates the metabolic inhibition by sodium fluoride, 3-bromopyruvate and mefloquine, but not by menadione. Note that, in the case of sodium fluoride, the effective concentration is very high (above $1 \mathrm{mM}$ ), which is most likely due to a reduced uptake of this compound by schistosomula. This phenomenon has also been described for adult schistosomes with at least $20 \mathrm{mM}$ sodium fluoride being necessary to inhibit glucose utilization in the parasites by $50 \%$ (Bueding, 1950). Our findings suggest that mefloquine directly interferes with glycolysis similar to the two inhibitors of glycolytic enzymes rather than acting indirectly as menadione. This assumption is corroborated by biochemical data.

Using affinity chromatography followed by mass spectrometry, we have identified the glycolytic enzyme enolase as a major mefloquine-binding protein in S. mansoni schistosomula. Enolase activity in schistosomula crude extracts is inhibited by mefloquine in a similar concentration range as by sodium fluoride. The recombinant enolase Q27877 is, however, not inhibited by either mefloquine or sodium fluoride. Moreover, the recombinant enolase has different kinetic parameters from the activity in crude extracts.

At first glance, these results suggest that mefloquine may inhibit an enolase isoform other than our recombinant Q27877. Mammals have 3 enolase isoforms, alpha, beta and gamma with multiple functions beside glycolysis (Pancholi, 2001) and for $S$. mansoni to date 2 isoforms of enolase, namely Q27877 and C4Q3S7, are listed in genomic databases. However, although these 2 isoforms are provided in genomic databases, it is likely that enolases other than Q27877 do not exist in S. mansoni. The small differences between Q27877 and $\mathrm{C} 4 \mathrm{Q} 3 \mathrm{~S} 7$, the protein derived from the genomic sequencing effort, are most likely due to errors, because the corresponding coding sequences are identical. A BLAST analysis showed that Q27877 
has $75 \%$ identity to human alpha-enolase, $72 \%$ to beta-enolase, and $71 \%$ to gamma-enolase and may thus fulfil-to a certain extent-the functional requirements for all classes in mammals.

More likely, enolase from crude extracts has been subjected to post-translational modifications and/or interacted with other proteins present in its natural cellular environment resulting in catalytic properties differing from the recombinant enzyme. For example, in mammalian cells such as human muscle fibres, enolases may be phosphorylated (Hojlund et al. 2009). The functional implication of this phosphorylation is unknown so far. In yeast, enolase is bound to vacuoles (Decker and Wickner, 2006) and may be part of a large macromolecular complex associated with mitochondria (Brandina et al. 2006). In Plasmodium, enolase has been described to have undergone post-translational modifications that are associated to different subcellular fractions (PalBhowmick et al. 2007). Taken together, these results indicate that a native enolase may be different from the recombinant enolase produced in $E$. coli. Results obtained with the latter may thus not reflect the original situation.

Moreover, there is increasing evidence that in S. bovis (Ramajo-Hernandez et al. 2007) and S. japonicum (Yang et al. 2010) enolase is localized not only intracellularly but also at the cell surface. The role of this localization is unclear, but extracellular enolase may be involved in the interaction with host proteins such as plasminogen or the immune system (Pancholi, 2001). It is possible that an extracellular, extensively modified enolase is the target for mefloquine. In $S$. japonicum, enolase is expressed in all developmental stages, but has higher expression levels in schistosomula than in adult worms suggesting that enolase is critical for growth, migration and adaption of the young schistosomes (Yang et al. 2010).

Overall, our results suggest, that in $S$. mansoni schistosomula, mefloquine inhibits enolase resulting in an interference with glycolysis and/or in debilitating the parasite via an unknown mechanism in the case of extracellular enolase. Since mefloquine has 3 fluorine residues, it is possible that it blocks enolase at the same site as fluoride ions as suggested in the scheme presented in Fig. 5. Fluoride forms a complex with magnesium and phosphate at the active site (Bunick and Kashket, 1982; Qin et al. 2006). There is, however, a non-deniable discrepancy between the concentrations of mefloquine inhibiting enolase activity in crude extracts and the nearly 1 magnitude lower concentrations needed for metabolic inhibition measured by microcalorimetry and by drug sensitivity assays (Manneck et al. 2011b). This suggests the existence of other molecular targets for mefloquine. Further work should focus on this aspect as well as on the role of enolase in the mode of action of mefloquine in Schistosoma spp.

\section{ACKNOWLEDGEMENTS}

We would like to thank Olivier Braissant for helpful discussions and his support concerning microcalorimetry and we are grateful to Corinne Lochmatter, Cristian Köpfli, Dania Müller and Yvette Endress for laboratory support. Furthermore, we would like to thank Professor Dr Andrew Hemphill (University of Berne) for his support.

\section{F INANCIAL SUPPORT}

T. M. and J. K. are grateful to the Swiss National Science Foundation (project no. PPOOA-114941) for financial support. J. M. is a recipient of a research fellowship provided by Novartis Animal Health.

\section{REFERENCES}

Altschul, S. F., Madden, T. L., Schaffer, A. A., Zhang, J., Zhang, Z., Miller, W. and Lipman, D. J. (1997). Gapped BLAST and PSI-BLAST: a new generation of protein database search programs. Nucleic Acids Research 25, 3389-3402.

Berriman, M., Haas, B. J., Loverde, P. T., Wilson, R. A., Dillon, G. P., Cerqueira, G. C., Mashiyama, S. T., Al-Lazikani, B., Andrade, L. F., Ashton, P.D., Aslett, M.A., Bartholomeu, D. C., Blandin, G., Caffrey, C. R., Coghlan, A., Coulson, R., Day, T.A., Delcher, A., Demarco, R., Djikeng, A., Eyre, T., Gamble, J. A., Ghedin, E., Gu, Y., Hertz-Fowler, C., Hirai, H., Hirai, Y., Houston, R., Ivens, A., Johnston, D. A., Lacerda, D., Macedo, C. D., Mcveigh, P., Ning, Z. Oliveira, G., Overington, J. P., Parkhill, J., Pertea, M., Pierce, R. J., Protasio, A. V., Quail, M. A., Rajandream, M. A., Rogers, J., Sajid, M., Salzberg, S. L., Stanke, M., Tivey, A. R., White, O., Williams, D. L., Wortman, J., Wu, W., Zamanian, M., Zerlotini, A., FraserLiggett, C. M., Barrell, B. G. and El-Sayed, N. M. (2009). The genome of the blood fluke Schistosoma mansoni. Nature, London 460, 352-358. Brandina, I., Graham, J., Lemaitre-Guillier, C., Entelis, N., Krasheninnikov, I., Sweetlove, L., Tarassov, I. and Martin, R.P. (2006). Enolase takes part in a macromolecular complex associated to mitochondria in yeast. Biochimica et Biophysica Acta 1757, 1217-1228.

Bueding, E. (1950). Carbohydrate metabolism of Schistosoma mansoni. The Fournal of General Physiology 33, 475-495.

Bunick, F. J. and Kashket, S. (1982). Binding of fluoride by yeast enolase. Biochemistry 21, 4285-4290.

Davis, R. E., Hardwick, C., Tavernier, P., Hodgson, S. and Singh, H. (1995). RNA trans-splicing in flatworms. Analysis of trans-spliced mRNAs and genes in the human parasite, Schistosoma mansoni. The Fournal of Biological Chemistry 270, 21813-21819.

Decker, B. L. and Wickner, W. T. (2006). Enolase activates homotypic vacuole fusion and protein transport to the vacuole in yeast. The Fournal of Biological Chemistry 281, 14523-14528.

Dorn, A., Vippagunta, S. R., Matile, H., Jaquet, C., Vennerstrom, J. L. and Ridley, R. G. (1998). An assessment of drug-haematin binding as a mechanism for inhibition of haematin polymerisation by quinoline antimalarials. Biochemical Pharmacology 55, 727-736.

Hojlund, K., Bowen, B. P., Hwang, H., Flynn, C. R., Madireddy, L., Geetha, T., Langlais, P., Meyer, C., Mandarino, L. J. and Yi, Z. (2009). In vivo phosphoproteome of human skeletal muscle revealed by phosphopeptide enrichment and HPLC-ESI-MS/MS. Fournal of Proteome Research 8, 4954-4965.

Keiser, J. (2010). In vitro and in vivo trematode models for chemotherapeutic studies. Parasitology 137, 589-603.

Keiser, J., Chollet, J., Xiao, S. H., Mei, J. Y., Jiao, P. Y., Utzinger, J. and Tanner, M. (2009). Mefloquine-an aminoalcohol with promising antischistosomal properties in mice. PLoS Neglected Tropical Diseases 3, e350.

Keiser, J., Vargas, M. and Doenhoff, M. J. (2010). Activity of artemether and mefloquine against juvenile and adult Schistosoma mansoni in athymic and immunocompetent NMRI mice. The American fournal of Tropical Medicine and Hygiene 82, 112-114.

Lochmatter, C., Schifferli, J. A. and Martin, P. J. (2009). Schistosoma mansoni TOR is a tetraspanning orphan receptor on the parasite surface. Parasitology 136, 487-498.

Manneck, T., Braissant, O., Ellis, W. and Keiser, J. (2011a). Schistosoma mansoni: antischistosomal activity of the four optical isomers and the two 
racemates of mefloquine on schistosomula and adult worms in vitro and in vivo. Experimental Parasitology 127, 260-269.

Manneck, T., Braissant, O., Haggenmüller, Y. and Keiser, J. (2011b). Isothermal microcalorimetry to study drugs against Schistosoma mansoni. Fournal of Clinical Microbiology 49, 1217-1225.

Manneck, T., Haggenmüller, Y. and Keiser, J. (2010). Morphological effects and tegumental alterations induced by mefloquine on schistosomula and adult flukes of Schistosoma mansoni. Parasitology 137, 85-98.

Müller, J., Sidler, D., Nachbur, U., Wastling, J., Brunner, T. and Hemphill, A. (2008). Thiazolides inhibit growth and induce glutathioneS-transferase Pi (GSTP1)-dependent cell death in human colon cancer cells. International fournal of Cancer 123, 1797-1806.

Oliveira, M.F., D'avila, J.C.P., Torres, C. R., Oliveira, P.L., Tempone, A. J., Rumjanek, F. D., Braga, C. M. S., Silva, J. R., DansaPetretski, M., Oliveira, M. A., De Souza, W. and Ferreira, S. T. (2000). Haemozoin in Schistosoma mansoni. Molecular and Biochemical Parasitology 111, 217-221.

Pal-Bhowmick, I., Vora, H. K. and Jarori, G. K. (2007). Sub-cellular localization and post-translational modifications of the Plasmodium yoelii enolase suggest moonlighting functions. Malaria fournal 6, 45.

Pancholi, V. (2001). Multifunctional alpha-enolase: its role in diseases. Cellular and Molecular Life Sciences 58, 902-920.

Pasternack, R.F., Munda, B., Bickford, A., Gibbs, E. J. and Scolaro, L. M. (2010). On the kinetics of formation of hemozoin, the malaria pigment. Fournal of Inorganic Biochemistry 104, 1119-1124.

Pelicano, H., Martin, D. S., Xu, R. H. and Huang, P. (2006). Glycolysis inhibition for anticancer treatment. Oncogene 25, 4633-4646.

Qin, J., Chai, G., Brewer, J. M., Lovelace, L. L. and Lebioda, L. (2006). Fluoride inhibition of enolase: crystal structure and thermodynamics. Biochemistry 45, 793-800.

Ramajo-Hernandez, A., Perez-Sanchez, R., Ramajo-Martin, V. and Oleaga, A. (2007). Schistosoma bovis: plasminogen binding in adults and the identification of plasminogen-binding proteins from the worm tegument. Experimental Parasitology 115, 83-91.

Renslo, A. R. and McKerrow, J.H. (2006). Drug discovery and development for neglected parasitic diseases. Nature Chemical Biology 2, 701710 .

Sleno, L. and Emili, A. (2008). Proteomic methods for drug target discovery. Current Opinion in Chemical Biology 12, 46-54.

Stefanic, S., Dvorak, J., Horn, M., Braschi, S., Sojka, D., Ruelas, D. S., Suzuki, B., Lim, K. C., Hopkins, S. D., Mckerrow, J.H. and Caffrey, C. R. (2010). RNA interference in Schistosoma mansoni schistosomula: selectivity, sensitivity and operation for larger-scale screening. PLoS Neglected Tropical Diseases 4, e850.

Van den Bossche, H. (1985). How anthelmintics help us to understand helminths. Parasitology 90, 675-685.

Verrax, J., Stockis, J., Tison, A., Taper, H.S. and Calderon, P. B. (2006). Oxidative stress by ascorbate/menadione association kills K562 human chronic myelogenous leukaemia cells and inhibits its tumour growth in nude mice. Biochemical Pharmacology 72, 671-680.

Warburg, O. and Christian, W. (1941). Chemischer Mechanismus der Fluorid-Hemmung der Gärung. Naturwissenschaften 29, 590.

Xiao, S. H., Mei, J.Y. and Jiao, P.Y. (2011). Effect of mefloquine administered orally at single, multiple, or combined with artemether, artesunate, or praziquantel in treatment of mice infected with Schistosoma japonicum. Parasitology Research 108, 399-406.

Yang, J., Qiu, C., Xia, Y., Yao, L., Fu, Z., Yuan, C., Feng, X. and Lin, J. (2010). Molecular cloning and functional characterization of Schistosoma japonicum enolase which is highly expressed at the schistosomulum stage. Parasitology Research 107, 667-677.

Zhang, J., Krugliak, M. and Ginsburg, H. (1999). The fate of ferriprotorphyrin IX in malaria infected erythrocytes in conjunction with the mode of action of antimalarial drugs. Molecular Biochemical Parasitology 99, 129-141. 